\title{
Stent Placement for Intracranial Cysts by Combined Stereotactic/Endoscopic Surgery
}

Ansgar Berlis, M.D.

Department of Neuroradiology, University Hospital Freiburg, Freiburg, Germany

Jan Vesper, M.D.

Department of Stereotactic Neurosurgery,

University Hospital Freiburg, Freiburg, Germany

Christoph Ostertag, M.D.

Department of Stereotactic

Neurosurgery,

University Hospital Freiburg,

Freiburg, Germany

Reprint requests:

Ansgar Berlis, M.D.,

Sektion Neuroradiologie,

Universitätsklinikum Freiburg,

Breisacherstr. 64,

D-79106

Freiburg, Germany.

Email: BERLIS@nz11.ukl.uni-

freiburg.de
OBJECTIVE: The treatment of space-occupying cystic lesions includes percutaneous cyst aspiration, marsupialization, percutaneous ventriculocystotomy, or Rickham catheter implantation. In some patients, the cysts tend to recur and repeated evacuations are necessary. The authors present a new treatment method with internal drainage of cysts into the ventricular system using a balloon-mounted vascular stent.

METHODS: Six patients with cysts of low-grade gliomas, one with monocystic craniopharyngioma, and one with suprasellar arachnoid cyst were treated between September 2003 and May 2005. All patients were symptomatic after multiple previous treatments. Stent implantations were performed under local anesthesia in adults and under general anesthesia in children. In all patients, the stereotactic frame and computed tomographic and magnetic resonance fusion were used for an optimized approach. The treatment was performed in a compassionate manner and the patients were informed about the off-label use of the device.

RESULTS: Stent placement was successful in all eight patients without procedurerelated complications. Improvement of clinical symptoms was seen in seven out of eight patients. Seven out of eight cysts decreased in size within a follow-up period of up to 23 months (mean, $17 \mathrm{mo}$; median, $18 \mathrm{mo}$; range, 6-23 mo). The first patient showed recurrence of the tumor cyst 3 months after initial treatment with a Herkulink stent $(5 \times 18 \mathrm{~mm})$, followed by retreatment with an Omnilink stent $(6 \times 28 \mathrm{~mm}$; Guidant Corp., Santa Clara, CA). Stenting was ineffective in one patient.

CONCLUSION: Treatment of intracranial cystic lesions by internal drainage is possible with the use of stent-assisted ventriculocystostomy.

KEY WORDS: Intracranial cysts, Neuroendoscopy, Stent, Stereotaxy, Ventriculocystostomy

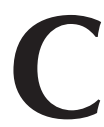
ysts of the brain can be divided into benign and tumorassociated cysts (10). Magnetic resonance imaging (MRI) demonstrates high signal intensity in T1-weighted images in tumor-associated cysts that characteristically contain protein-rich fluid. The so-called benign cysts, such as arachnoid, neuroepithelial, leptomeningeal, and porencephalic cysts, show cerebrospinal fluid (CSF)-like signal intensity in T1- and T2-weighted images.

In particular, primary and metastatic brain tumors may be accompanied by cystic lesions that may become large enough to cause compression of surrounding brain, resulting in signs and symptoms of either raised intracranial pressure or focal neurological deficits. Apart from these primary cysts, space-occupying cystic lesions also may develop in a variable time after resection or radiation therapy or chemotherapy $(4,8,12,14,19,20)$. The pathomechanism of the cyst formations remains unclear, but a causal relationship with previous radiation therapy, chemotherapy, or infectious or bleeding complications is presumed $(14,19)$.
Reduction in cyst size may be accomplished by therapy directed at the tumor, including resection, radiation, chemotherapy, or a combination of these. However, cysts may recur after brain tumor treatment and in some instances may develop as a consequence of treatment $(14,19)$. Stereotactic placement of a Rickham catheter or an Ommaya reservoir or ventriculocystostomy avoids multiple cyst aspirations. Nevertheless, in some cases, successive treatments are necessary because of occlusion of the catheter or ventriculocystostomy. We present a new technique with stent-assisted ventriculocystostomy in eight patients who were treated in a compassionate manner.

\section{PATIENTS AND METHODS}

Eight patients (age range, 8-63 yr) were treated between September 2003 and May 2005 (Table 1). One patient was treated twice after cyst recurrence. The treatments were per- 


\section{TABLE 1. Summary of clinical characteristics ${ }^{a}$}

\begin{tabular}{|c|c|c|c|c|c|}
\hline Patient no. $A$ & Age (yr)/sex & Diagnosis & Previous treatment & Stent $^{b}$ & Follow-up \\
\hline 1 & $29 / M$ & $\begin{array}{l}\text { Optic glioma } \\
\text { WHO Grade I }\end{array}$ & $\begin{array}{l}\text { Stereotactic biopsy, } 02 / 84 ; 3 \\
\text { Rickham catheter reservoir, first } \\
\text { 12/91; recurrent cyst puncture }\end{array}$ & $\begin{array}{l}\text { 09/03, (Herkulink } \\
5.0 \times 18 \mathrm{~mm})(\mathrm{i}) \\
01 / 04, \text { Omnilink } \\
6.0 \times 28 \mathrm{~mm} \text { (ii) }\end{array}$ & $\begin{array}{l}\text { Initially improved, recurrent cyst after } \\
2 \text { months with hemisymptomatic (i); } \\
\text { immediately improved, stable over 23- } \\
\text { month follow-up; evident decrease of } \\
\text { cyst size (ii) }\end{array}$ \\
\hline 2 & $51 / \mathrm{M}$ & $\begin{array}{l}\text { Oligodendroglioma } \\
\text { WHO Grade II }\end{array}$ & $\begin{array}{l}\text { Stereotactic biopsy, 01/95; } \\
\text { recurrent cyst puncture ( } 14 \\
\text { times) and Rickham catheter } \\
\text { implantation ( } 4 \text { times); radiation } \\
\text { therapy, } 11 / 01 \text { (50 Gy) }\end{array}$ & $\begin{array}{l}\text { 07/04, Omnilink } \\
6.0 \times 28 \mathrm{~mm}\end{array}$ & $\begin{array}{l}\text { Immediate improvement, stable over } \\
\text { 6-month follow-up (on MRI scan and } \\
\text { clinically); clinically stable over } 18 \\
\text { months (MRI scan during follow-up } \\
\text { declined); evident decrease of cyst size }\end{array}$ \\
\hline 3 & $13 / F$ & $\begin{array}{l}\text { NF type } 1, \\
\text { optic tract glioma } \\
\text { WHO Grade I }\end{array}$ & $\begin{array}{l}\text { Stereotactic biopsy, 1997; } \\
\text { recurrent cyst punctures; } \\
\text { Rickham catheter implantation, } \\
09 / 01 \text {; interstitial radiosurgery } \\
\left(J^{125}\right)\end{array}$ & $\begin{array}{l}\text { 04/04, Omnilink } \\
6.0 \times 28 \mathrm{~mm}\end{array}$ & $\begin{array}{l}\text { Immediate improvement, stable over } \\
\text { 18-month follow-up; evident decrease } \\
\text { of cyst size }\end{array}$ \\
\hline 4 & $49 / F$ & $\begin{array}{l}\text { Suprasellar } \\
\text { arachnoidal cyst }\end{array}$ & $\begin{array}{l}\text { Recurrent cyst puncture since } \\
\text { 07/00 and endoscopic } \\
\text { fenestration; surgery declined }\end{array}$ & $\begin{array}{l}\text { 05/04, Omnilink } \\
6.0 \times 28 \mathrm{~mm}\end{array}$ & $\begin{array}{l}\text { Immediate improvement, stable over } \\
\text { 19-month follow-up (on MRI scan and } \\
\text { clinically); clinically stable over } 22 \\
\text { months; evident decrease of cyst size }\end{array}$ \\
\hline 5 & $8 / F$ & $\begin{array}{l}\text { NF type } 1, \\
\text { hypothalamic and } \\
\text { chiasma glioma } \\
\text { WHO Grade I }\end{array}$ & $\begin{array}{l}\text { Stereotactic biopsy and } \\
\text { interstitial radiosurgery, 03/01; } \\
\text { recurrent cyst punctures }\end{array}$ & $\begin{array}{l}\text { 03/04, Omnilink } \\
6.0 \times 28 \mathrm{~mm}\end{array}$ & $\begin{array}{l}\text { Immediate improvement after stenting, } \\
\text { stable over } 21 \text {-month follow-up; } \\
\text { evident decrease of cyst size }\end{array}$ \\
\hline 6 & $10 / \mathrm{M}$ & $\begin{array}{l}\text { Pilocytic astrocytoma } \\
\text { WHO Grade I }\end{array}$ & $\begin{array}{l}\text { Partial resection, 1997; } \\
\text { interstitial radiosurgery, } 1998 \\
\text { and 2002; Rickham catheter } \\
\text { implantation with recurrent cyst } \\
\text { punctures }\end{array}$ & $\begin{array}{l}\text { 10/04, Omnilink } \\
6.0 \times 28 \mathrm{~mm}\end{array}$ & $\begin{array}{l}\text { Cyst stable over 12-month follow-up; } \\
\text { clinical improvement and seizure free; } \\
\text { cyst with slight decrease in size }\end{array}$ \\
\hline 7 & $19 / F$ & $\begin{array}{l}\text { Pilocytic astrocytoma } \\
\text { WHO Grade I }\end{array}$ & $\begin{array}{l}\text { Stereotactic biopsy and } \\
\text { interstitial radiosurgery, 11/97 }\end{array}$ & $\begin{array}{l}\text { 11/04, Omnilink } \\
6.0 \times 28 \mathrm{~mm}\end{array}$ & $\begin{array}{l}\text { No improvement; obstructive } \\
\text { hydrocephalus; surgery with } \\
\text { hemorrhage }\end{array}$ \\
\hline 8 & $63 / M$ & Craniopharyngioma & $\begin{array}{l}\text { Cyst puncture 2002; surgery } \\
\text { declined }\end{array}$ & $\begin{array}{l}\text { 5/05, Omnilink } \\
6.0 \times 28 \mathrm{~mm}\end{array}$ & $\begin{array}{l}\text { Immediate improvement after stenting; } \\
\text { stable over 6-month follow-up; evident } \\
\text { decrease of cyst size }\end{array}$ \\
\hline
\end{tabular}

${ }^{a}$ WHO, World Health Organization; i, first treatment; ii, second treatment 3 months later; MRI, magnetic resonance imaging; NF, neurofibromatosis.

${ }^{b}$ The Omnilink and Herkulink stents were manufactured by Guidant Corp., Santa Clara, CA.

formed under local anesthesia in adults and under general anesthesia in children.

A three-dimensional data set (contrast-enhanced T1weighted magnetization prepared rapid acquisition gradient echo with 1-mm slice thickness) and an axial T2-weighted sequence were acquired using a 1.5-T whole body imaging system. After transfer of data to the planning computer (STP4; Leibinger-Stryker-Howmedica, Freiburg, Germany), a coregistration of MRI and contrast-enhanced computed tomographic (CT) analysis with stereotactic frame was established by using anatomic landmarks (Fig. 1).

After burr-hole trepanation, a rigid neuroendoscope with 0-degree Hopkins-Optic (Karl Storz GmbH, Tuttlingen, Germany) was introduced. The endoscope was $30 \mathrm{~cm}$ in length with an outer diameter of $2.8 \mathrm{~mm}$ and one working channel. After puncture of the cyst, only a small amount of fluid was aspirated to prevent cyst collapse. The cyst was filled with contrast medium to establish a better delineation of the cyst and ventricular system. Under biplane fluoroscopy control, the balloon-mounted stainless steel stent (uninflated balloon/stent with a maximum diameter of $1.63 \mathrm{~mm}$ ) was pushed forward through the guide cannula $(3.5 \mathrm{~mm})$ of the endoscope and placed with the distal end inside the cyst and the proximal end inside the ventricle. The balloon was inflated with nominal pressure of 8 atmospheres according to a stent diameter of 5 versus $6 \mathrm{~mm}$ (Fig. 2). Herkulink stents (5 x 18 mm; Guidant Corporation, Santa Clara, CA) were used in one patient and Omnilink stents $(6 \times 28 \mathrm{~mm}$; Guidant Corporation) were used in eight patients (Fig. 3). After deployment of the stents, the balloon catheter was removed and the position was controlled endoscopically.

Two different surgical strategies for stent placement were used. Seven patients with eight treatments were treated with 

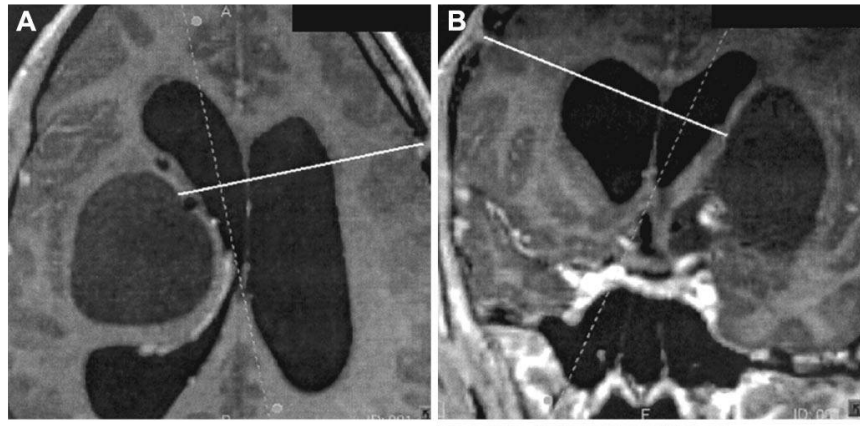

FIGURE 1. Stereotactic image fusion for an optimized endoscopic approach in a 29-year-old man (Patient 1) with a large tumor cyst. The white lines demonstrate the planned trajectory to connect the right ventricle with the cyst (A, axial view; $\mathrm{B}$, coronal view; $\mathrm{C}$, sagittal view).

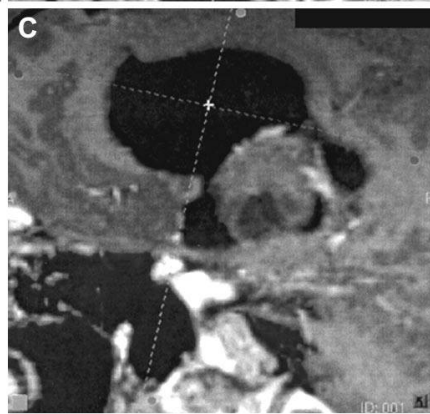

ventricular-cyst access and one patient was treated with cystventricular access. Surgery was followed immediately by control CT examination in the stereotactic frame. Control MRI analysis was performed within 4 days, and follow-up examinations were acquired at 3-month intervals. X-ray control was carried out within the first several days after surgery.

\section{RESULTS}

Six patients with cysts of low-grade gliomas, one with monocystic craniopharyngioma, and one with a suprasellar arachnoid cyst were treated. All patients were symptomatic with enlarged recurrent cysts after multiple treatments and with focal neurological symptoms in seven patients and seizures in one patient (Patient 6). In all patients, surgery was carried out with a stereotactic frame and CT and/or MRI fusion, which was useful for an optimized approach.

Within 4 days, reduction in cyst size was evident in six out of eight patients, and MRI scans showed that the initially protein-rich cyst fluid was exchanged with CSF, because of free flow of CSF between the cyst and ventricle in four out of six patients (Figs. 4-6). Further major reduction of cyst size was seen in the follow-up examinations of six patients and minor reduction in size was seen in one patient (Table 1). The median follow-up period was 18 months (mean, 17 mo; range, 6-23 mo).

Patient 1 (Table 1) was treated twice (Figs. 1, 2, 4 and 5). During the first treatment, a Herkulink stent $(5 \times 18 \mathrm{~mm})$ was implanted (Fig. 2). Three months after initial improvement, the patient returned to the same condition with left-sided hemiparesis. MRI scans revealed a regrowth of the tumor cyst because the length of the stent was too short, ending at the cyst margin. After collapsing of the cyst, the end of the stent was
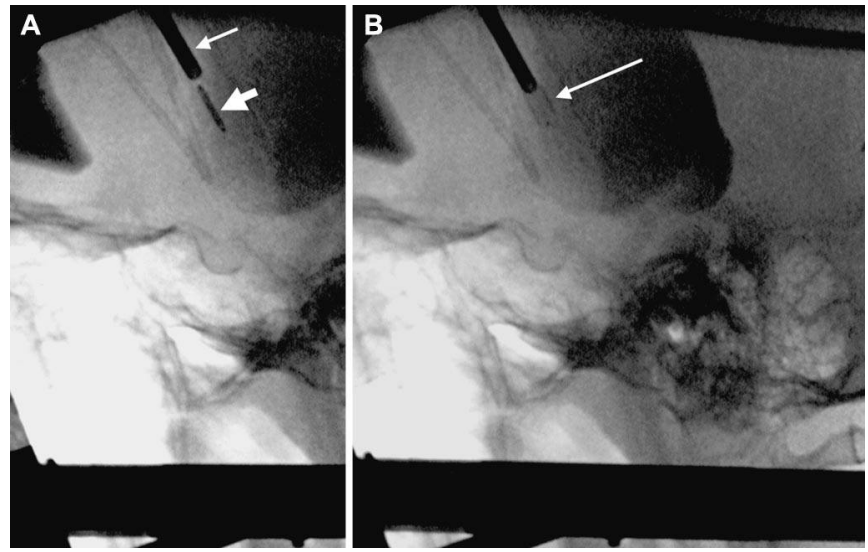

FIGURE 2. Lateral view $x$-rays of Patient 1 showing a contrast-filled tumor cyst. The stent catheter (Herkulink $5 \times 18$, thick arrow) was pushed forward through the guiding cannula (thin arrow). A, the stent was placed under fluoroscopy in position. B, the stent is deployed and the balloon catheter is in still in place, but deflated (arrow). Note the three implanted Rickham catheters, which were all occluded.

isolated from the cyst and internal drainage was impossible. In a second procedure via the same approach, a longer stent (Omnilink $6 \times 28 \mathrm{~mm}$ ) was implanted, with the longer part inside the cyst and the shorter part inside the lateral ventricle. A follow-up MRI scan (Fig. 5) showed the significant decrease of cyst size with the stent still inside the residual cyst and reduced mass effect. As a consequence, for all other patients, the Omnilink stent $(6 \times 28 \mathrm{~mm})$ was used.

Patient 7 showed spontaneous hemorrhage inside the basal ganglia tumor cyst before stenting, with an increase of cyst size within a few days between MRI (cyst size, $6 \times 5 \times 5 \mathrm{~cm}$ ) and stereotactic frame CT examination (cyst size, $7 \times 6 \times 6$ $\mathrm{cm}$ ). The patient experienced hydrocephalus resulting from obstruction of the foramen of Monro. The stenting of the enlarged cyst was without problems, but exchange of tumor cyst fluid, blood, and CSF was impossible because of preexisting obstructive hydrocephalus. Because of deterioration, the patient underwent craniotomy for tumor resection and for intracystic hemorrhage, which was complicated by intraparenchymal hemorrhage.

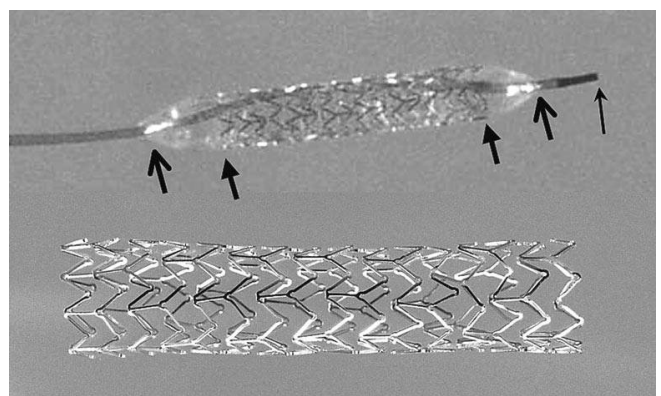

FIGURE 3. Mounted and deployed Omnilink stent with inflated balloon. Note that the balloon overlaps both ends of the stent for approximately 5 $\mathrm{mm}$ and the tip of the catheter for another $5 \mathrm{~mm}$. 
Procedure-related complications, such as hematomas, did not occur. Except for one patient with retreatment, follow-up MRI analysis and clinical examinations had unremarkable results. None of the patients experienced a communicating
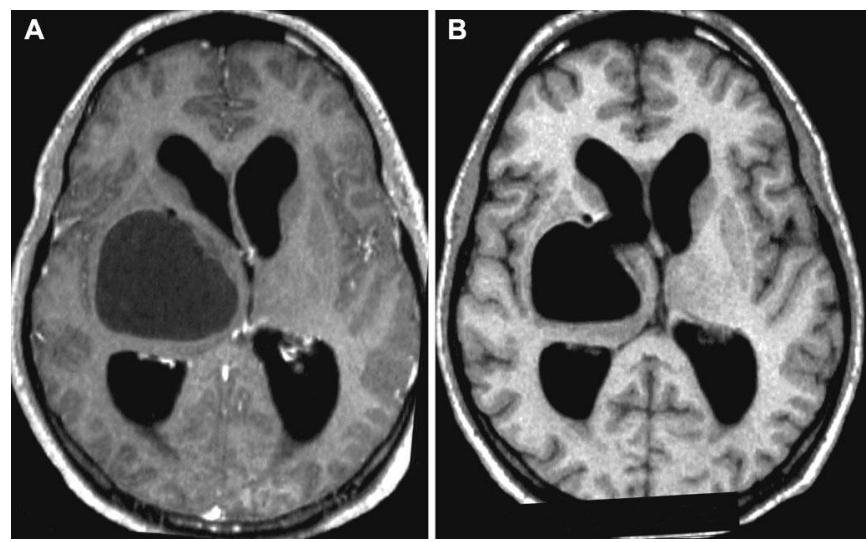

FIGURE 4. Patient 1. MRI scans obtained before surgery (A) and 3 days after surgery $(\mathrm{B})$ showing the first stent placement (Herkulink $5 \times 18$ ) with an exchange of initial high signal intensity cyst fluid with cerebrospinal fluid-like intensity fluid. The stent artifacts end at the cyst border. hydrocephalus that may be a result of permanent communication between a protein-rich tumor cyst and ventricle.

\section{DISCUSSION}

In general, approximately $10 \%$ of tumors of the central nervous system are accompanied by fluid-filled cystic components (1). Gliomatous cysts have been reported to occur in $20 \%$ of oligodendrogliomas, $40 \%$ of glioblastomas, 25 to $54 \%$ of supratentorial gliomas, and 55 to $70 \%$ of pediatric astrocytomas $(5-7,12,13,20)$.

The pathogenesis of cysts accompanying gliomatous and metastasis in the central nervous system is based on bloodbrain barrier disruption followed by exudation of plasma proteins into the brain parenchyma, with formation of edema and transition of edematous tissue $(10,11,18)$. Other fluidfilled cysts of the central nervous system, such as craniopharyngeal cysts, colloid cysts, neuroepithelial cysts such as ependymal cysts and plexus cysts, and arachnoid cysts, are not the result of blood-brain barrier disruption (11).

The recurrence of cysts after tumor surgery, for which placement of shunts and Rickham or Ommaya drains has been suggested, has been described $(9,15)$. Advances in neuroendoscopic surgery have enabled less invasive approaches to various intracranial diseases, and a variety of treatment strategies like endoscopic plasty or catheter placements has been described $(2,3,16,17)$. A silicone catheter has been implanted to construct a permanent communication between a craniopharyngeal cyst and the lateral or third ventricle or for aqueductal stenting. Up to now, the use of balloon-mounted stainless steel stents for treatment of intracranial cysts has not been described in the literature.

The main advantage of using a balloon-expandable stent is the permanent wide communication between cyst and ventricle. After cyst shrinkage, the occlusion of the communication may be possible if only balloon plasty has been attempted. Another advantage seems to be the stent porosity, which allows fluid passage through the stent struts across the entire stent length. Patient 1 initially was treated with a $5 \times$ 18-mm Herkulink stent. After clinical and morphological improvement, the cyst increased
FIGURE 5. Patient 1. First column, control MRI scans obtained 3 months after second stent placement stent placement showing a recurrent tumor cyst. Control MRI scans obtained 3 days (second column), 9 months (third column), and 23 months (fourth column) after second stent placement. MRI scans showed an improvement of the mass effect, as well as an evident reduction of the cyst size. 


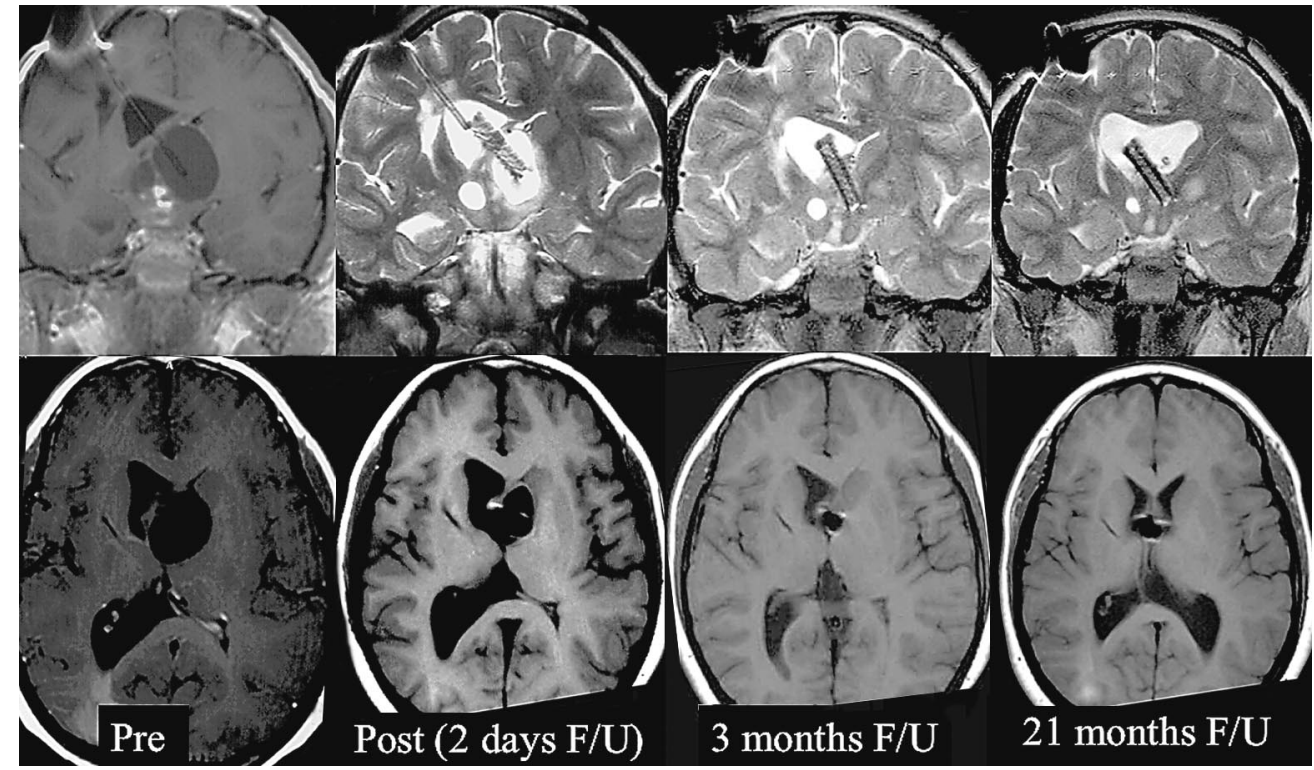

FIGURE 6. MRI scans of an 8-year-old girl showing neurofibromatosis 1, optic glioma, and recurrent tumor cyst obtained before treatment and 3 days, 3 months, and 21 months after stent placement (Omnilink $6 \times 28$ $\mathrm{mm}$ ) showing an optimal result with nearly complete regression of the cystic lesion.

and the initially intracystic end of the stent shifted to the cyst border, preventing a free communication. Therefore, a $6 \times$ 28-mm Omnilink stent was implanted with the stent predominantly inside the cyst, which avoided recurrence of the cyst (Figs. 4 and 5).

Our short-term results with a median follow-up period of 18 months demonstrate the long-lasting patency of the stents. Presently, experience with tissue in-growth and possible occlusion of the stent lumen does not exist. In Patient 4, the stent was placed from the suprasellar arachnoidal cyst through the hypothalamus to the left lateral ventricle. The follow-up MRI examinations did not reveal gliosis in the stent environment.

Various types of intravascular stents have been evaluated for safety with MRI systems. According to the published tables (www.mrisafety.com/home.asp), both stents used in this study are safe: the Herculink stent at 1.5-T and the Omnilink stent at 3.0-T field strength. Our examinations were carried out exclusively using a 1.5-T scanner (Siemens Vision, Erlangen, Germany), and we have not documented any adverse events. Nevertheless, the safety profile is limited because the stents were not placed intravascularly.

Occlusion and adherence of the inner lumen of the Rickham catheter or Ommaya reservoir are known to occur after implantation inside a protein-rich tumor cyst. Our preliminary results with stents demonstrate that occlusion can be avoided when the stent diameter is wide enough and is positioned properly.

The main advantage of using stents seems to be that they can be navigated to the region of interest with a smalldiameter probe during introduction (a 1.63- $\mathrm{mm}$ diameter of the deflated 6-mm Omnilink stent). Introducing a 6-mm silicone catheter is not as atraumatic as introducing a $1.63-\mathrm{mm}$ stent through a guiding cannula of the endoscope with a 3.5-mm diameter. This kind of balloon-mounted stent was designed for vascular diseases. A minor problem is that there is a distance of approximately $1 \mathrm{~cm}$ between the end of the stent and the end of the catheter; also, they are not fully appropriate for stent-assisted ventriculocystostomy. Furthermore, there is an overlap between the balloon and the mounted stent of approximately $5 \mathrm{~mm}$, and there is another $5 \mathrm{~mm}$ between the balloon and the catheter tip (Fig. 3). Nevertheless, in all patients, the stent could be placed adequately. In all patients, the stereotactic frame was used. Principally, frameless navigation is possible, but the stereotactic device allows a high grade of accuracy and instrument stability, while correcting of the guiding cannula or endoscope position is possible. In conclusion, our preliminary results with this new technique of stent-assisted ventriculocystostomy seems to be more favorable than other treatment strategies, such as endoscopic plasty, placement of silicone catheter, or implantation of drains.

\section{CONCLUSION}

Many procedures have been used in the treatment of intracranial cystic lesions, mainly percutaneous cyst aspiration, marsupialization, percutaneous ventriculocystostomy with or without plasty, and cyst drainage. In some patients, the procedures were unsuccessful and the cyst increased in size, causing neurological disturbances. Therefore, repeated evacuations that include the use of different methods are necessary.

We present a new technique with stent-assisted ventriculocystostomy by combined stereotactic/endoscopic surgery in patients with recurrent cysts after multiple previous treatments. Our initial results demonstrate the role of the balloonmounted stainless steel stent with the possibility of a permanent communication between cyst and ventricle. The main advantages of stent use are the porosity of the stent struts, which allow a free communication of the cystic fluid and the CSF along the entire stent length, and a stent diameter of approximately $6 \mathrm{~mm}$, which helps to keep open the ventriculocystostomy. Although our initial results are encouraging, a larger number of patients and longer follow-up will be necessary to determine definitively the effect of a stent on the durability of stent-assisted ventriculocystostomy. 


\section{REFERENCES}

1. Afra D, Norman D, Levin VA: Cysts in malignant gliomas. Identification by computerized tomography. J Neurosurg 53:821-825, 1980.

2. Bulsara KR, Villavicencio AT, Shah AJ, McGirt MJ, George TM: Successful aqueductal plasty and stenting for tectal plate tumor after failed third ventriculostomy: A case report. Surg Neurol 59:58-62, 2003.

3. Ebel H, Rieger A, Spies EH, Böker DK: Stereotactic cysto-ventricular shunting in diencephalic (arachnoid) cysts and failure in cystic craniopharyngioma. Minim Invasive Neurosurg 38:41-47, 1995.

4. Engelhard HH: Tumor bed cyst formation after BCNU wafer implantation: Report of two cases. Surg Neurol 53:220-224, 2000.

5. Frankel SA, German WJ: Glioblastoma multiforme: Review of 219 cases with regard to natural history, pathology, diagnostic methods and treatment. J Neurosurg 15:489-503, 1958.

6. Gol A: The relatively benign astrocytomas of the cerebrum. A clinical study of 194 verified cases. J Neurosurg 18:501-506, 1961.

7. Hood TW, McKeever PE: Stereotactic management of cystic gliomas of the brain stem. Neurosurgery 24:373-378, 1989.

8. Korinth MC, Weinzierl MR, Krings T, Gilsbach JM: Occurrence and therapy of space-occupying cystic lesions after brain tumor surgery. Zentralbl Neurochir 62:87-92, 2001.

9. Loftus CM, Copeland BR, Carmel PW: Cystic supratentorial gliomas: Natural history and evaluation of modes of surgical therapy. Neurosurgery 17:19-24, 1985.

10. Lohle PN, Verhagen IT, Teelken AW, Blaauw EH, Go KG: The pathogenesis of cerebral gliomatous cysts. Neurosurgery 30:180-185, 1992.

11. Lohle PN, Wurzer HA, Seelen PJ, Kingma LM, Go KG: The pathogenesis of cysts accompanying intra-axial primary and metastatic tumors of the central nervous system. J Neurooncol 40:277-285, 1998.

12. McGirt MJ, Villavicencio AT, Bulsara KR, Friedman HS, Friedman AH: Management of tumor bed cysts after chemotherapeutic wafer implantation. J Neurosurg 96:941-945, 2002.

13. Mercuri S, Russo A, Palma L: Hemispheral supratentorial astrocytoma in children: Long term results in 29 cases. J Neurosurg 55:170-173, 1981.

14. Poisson M, Philippon J, van Effenterre R, Racadot J, Sichez JP: Cerebral pseudocysts following chemotherapy of glioblastomas. Acta Neurochir 39: 143-149, 1977.

15. Rogers LR, Barnett GB: Percutaneous aspiration of brain tumor cysts via the Ommaya reservoir. Neurology 41:279-282, 1991.

16. Schroeder HW, Gaab MR: Endoscopic aqueductoplasty: Technique and results. Neurosurgery 45:508-518, 1999.

17. Shin M, Morita A, Asano S, Ueki K, Kirino T: Neuroendoscopic aqueductal stent placement procedure for isolated fourth ventricle after ventricular shunt placement. J Neurosurg 92:1036-1039, 2000.

18. Tomita T, McLone D, Naidich T: Mural tumors with cysts in the cerebral hemispheres of children. Neurosurgery 19:998-1005, 1986.

19. Volc D, Jellinger K, Flament H, Böck F, Klumair J: Cerebral space-occupying cysts following radiation and chemotherapy of malignant gliomas. Acta Neurochir 57:177-193, 1981.

20. Wise BL: Large basal ganglia cyst in site of previously radiated glioma. Case report. Neurosurgery 1:284-286, 1977. 